\title{
Nighttime Safety Belt Use
}

Presenter: Richard P. Compton

National Highway Traffic Safety Administration 202-366-9591

Richard.Compton@nhtsa.dot.gov

Principle Investigator: Neil K. Chaudhary

Preusser Research Group Inc.

nchaudhary@preussergroup.com 


\section{The Problem}

- In $2002,26 \%$ of traffic related fatalities* occurred between the hours of $10 \mathrm{pm}$ and 3:39am

- This window of time represents $25 \%$ of the day

- BUT less than $10 \%$ of daily traffic occurs during this time 


\section{The Problem}

Office of Research and Technology

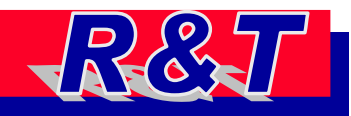

$\%$ Belted among fatally injured front seat occupants of passenger vehicles

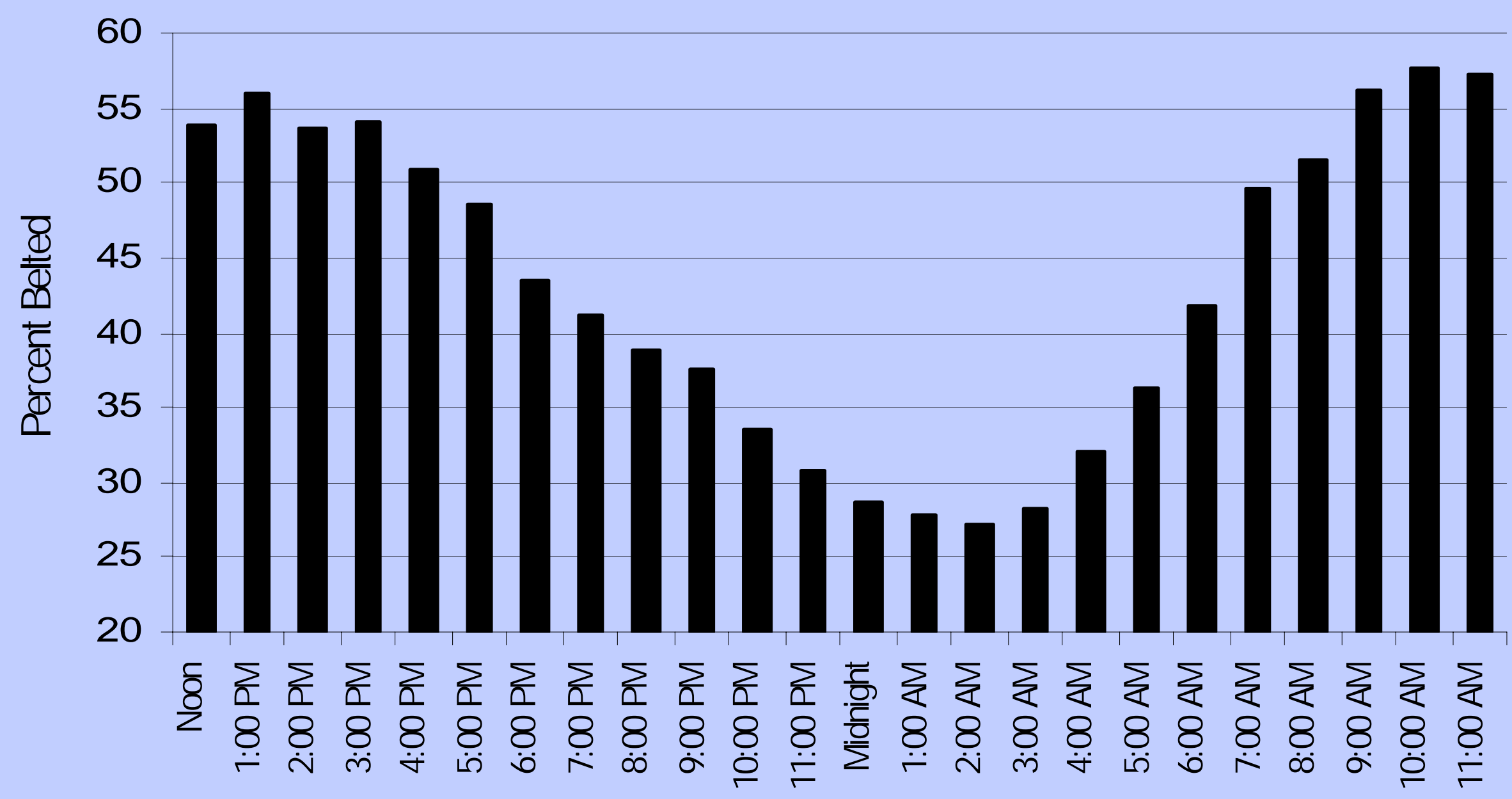

Source: FARS 2002, 2003 


\section{Problem}

- Belt use rates are daytime use rates

- Belt use at night is generally "unknown" 


\section{Evaluation/Enforcement Difficulties}

- Nighttime belt observations 


\section{Evaluation/Enforcement Difficulties}

- Move to lighted locations?

What about rural areas?

Move daytime locations also? 


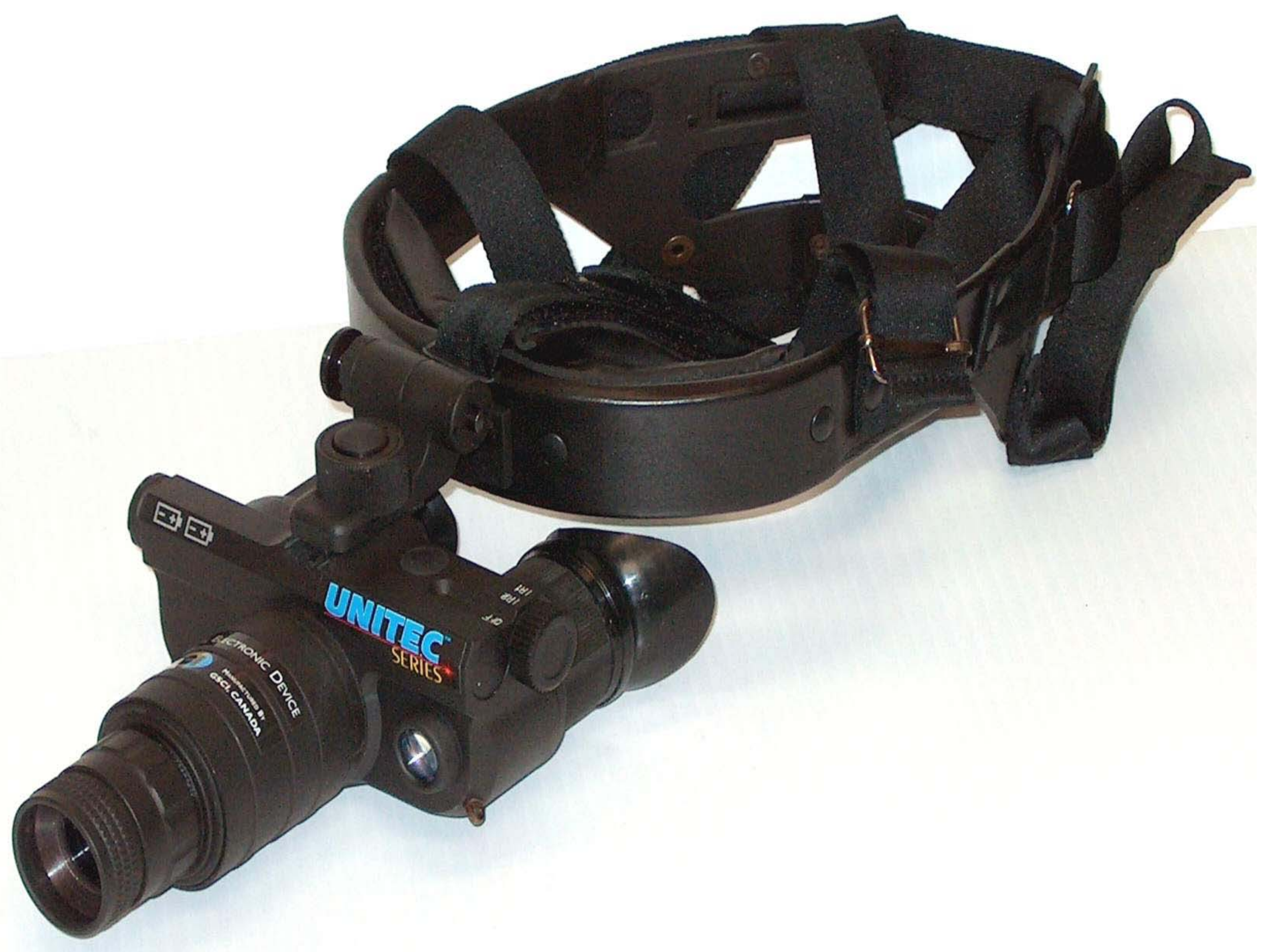




\section{New Nightvision}

\section{Office of Research and Technology}

R\&政

GEN 3

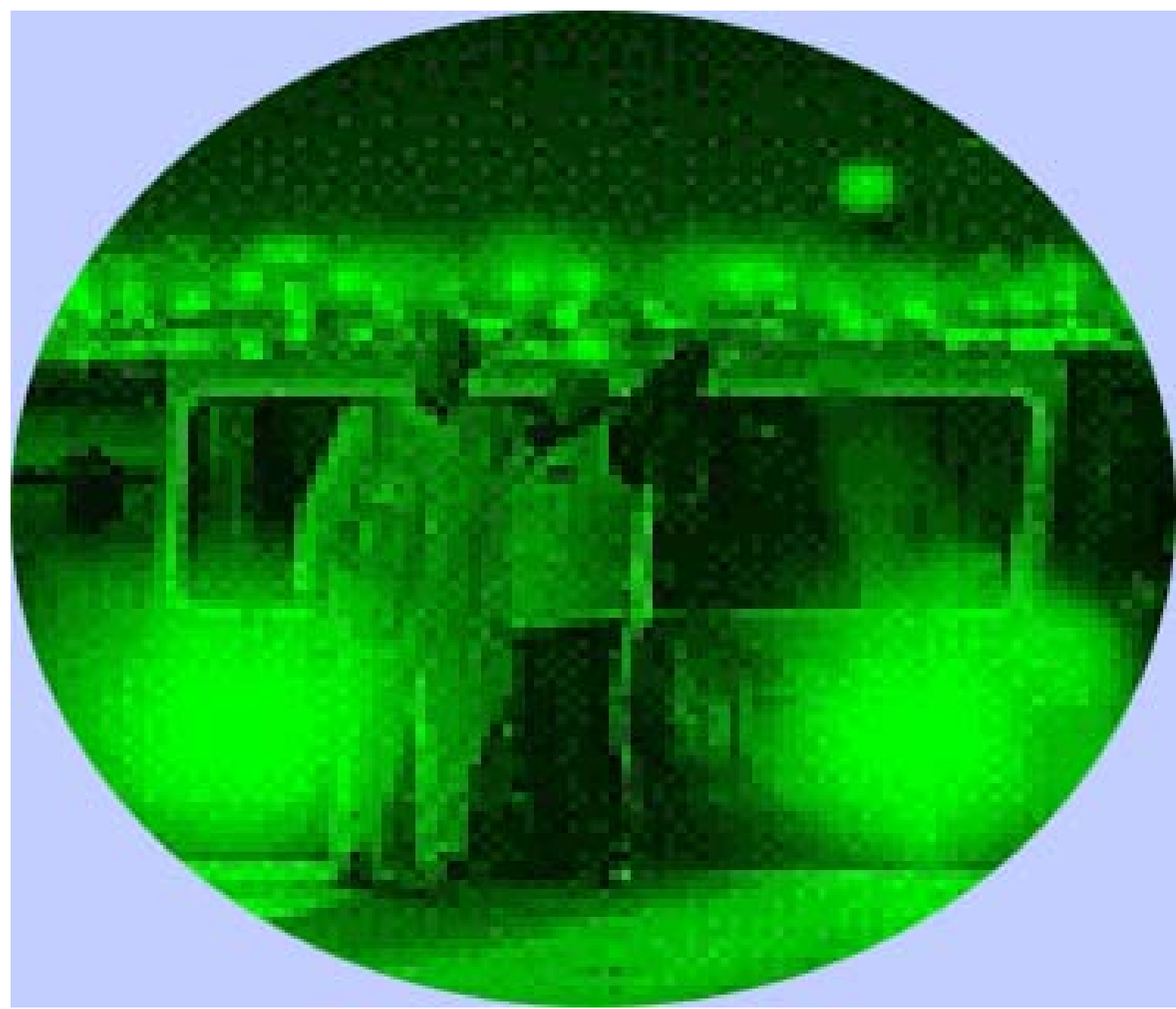




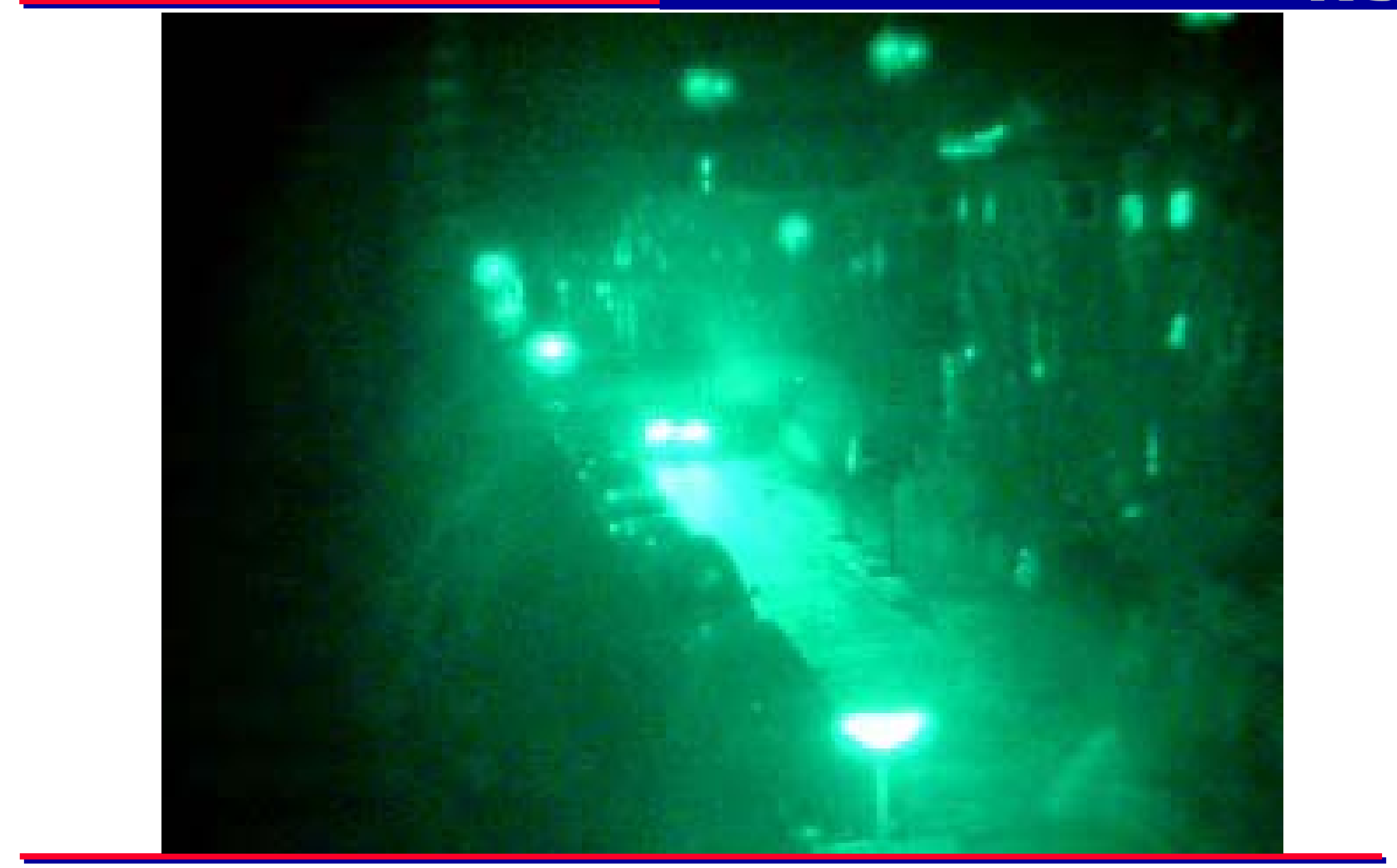




\section{The View}

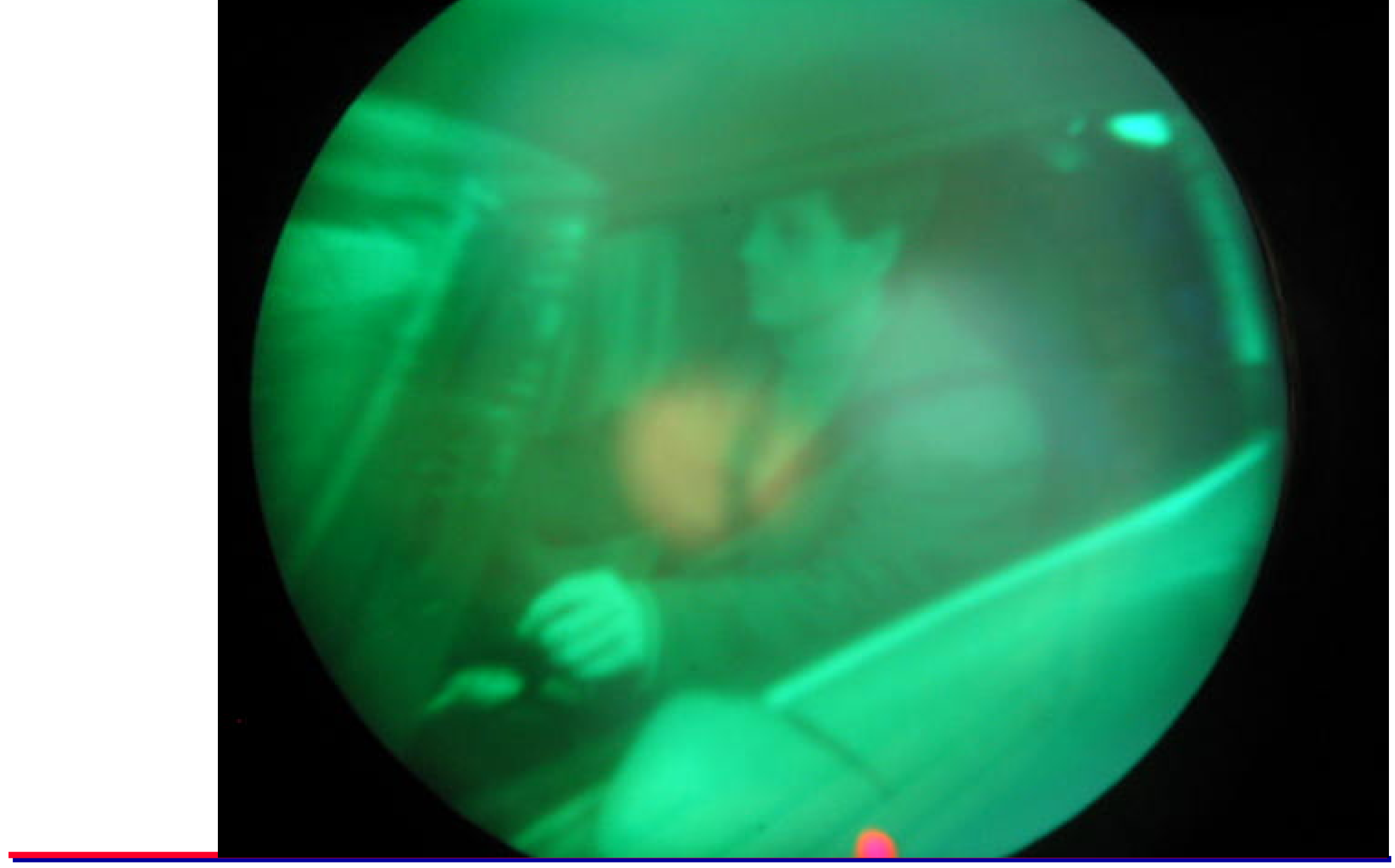




\section{Statewide Night Belt}

- Statewide "157 compliant" night belt use observation surrounding CIOT

Sites: same as day (usually) with NV goggles

- Even w/NV some sites impossible to view

Weighting based on traffic counts

- Day time use 24-hour traffic counts

- Relative traffic density by functional class changes at night

- Must use counts for night hours only 


\section{Night Observations}

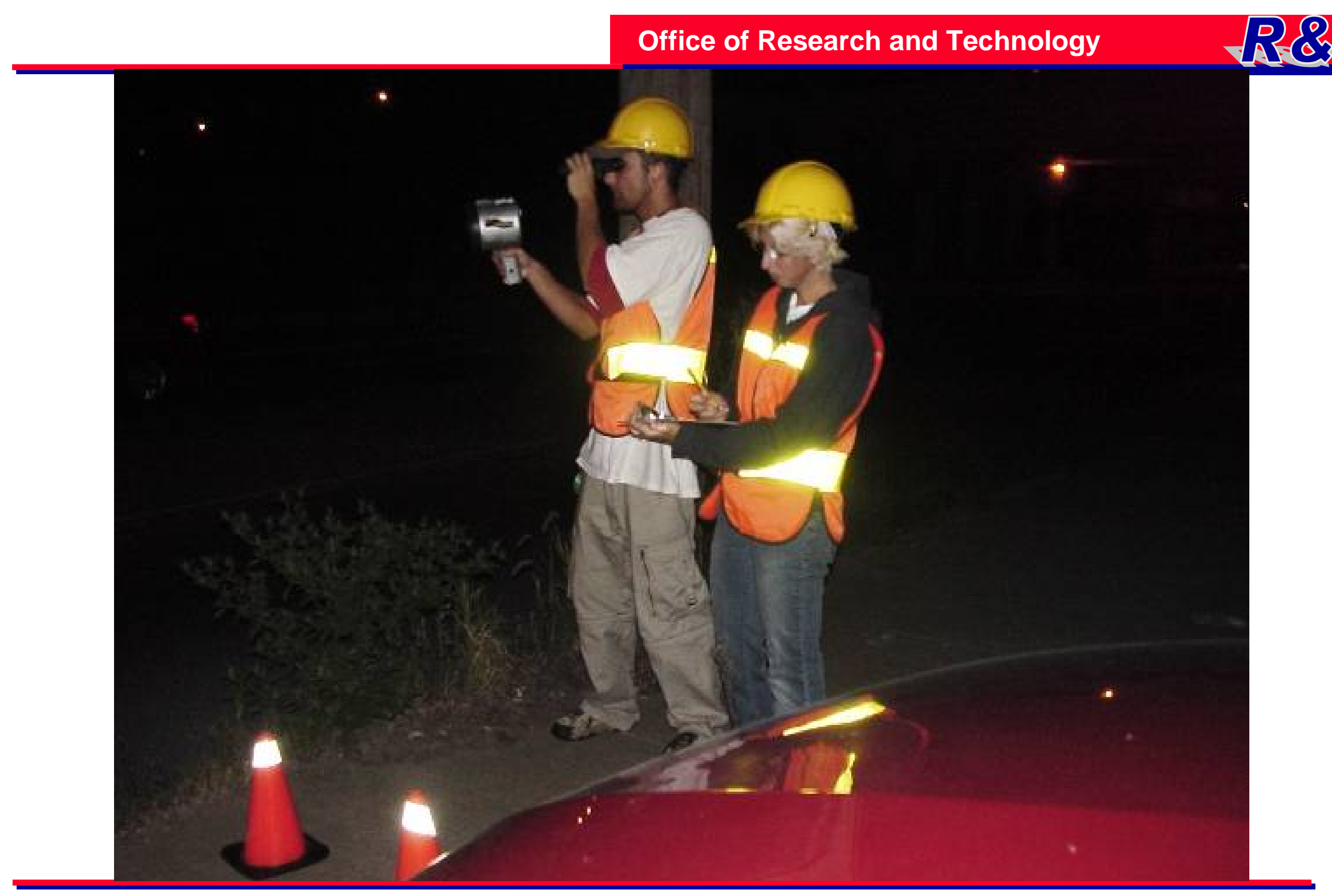




\section{Night Observations}

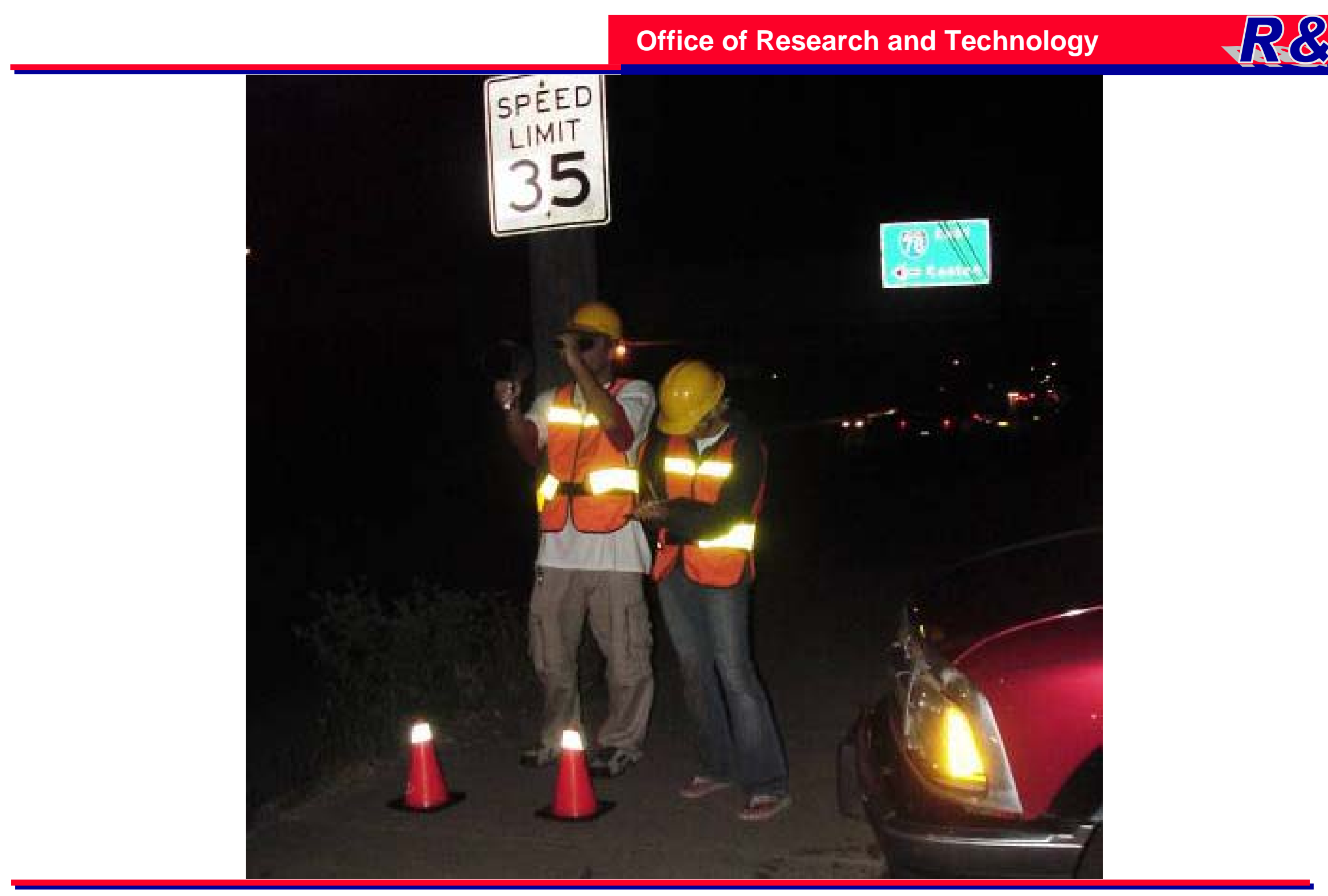




\section{CT Statewide Nighttime Belt Use}

\section{Weighted Statewide Belt Use}

$84.0 \%$

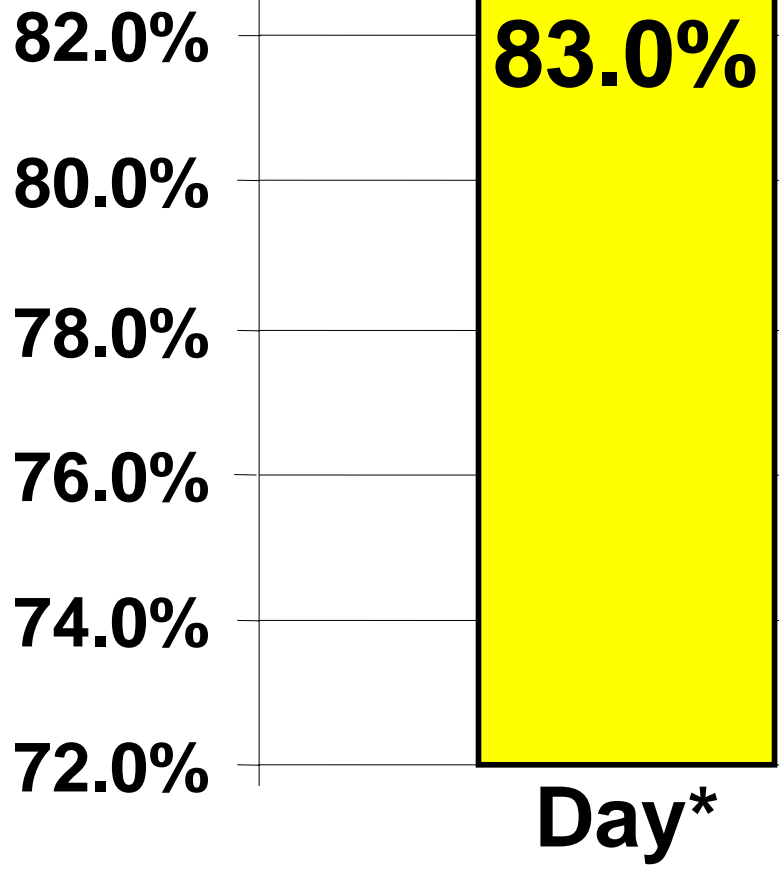

\section{$76.6 \%$}

Night

* The Statewide survey submitted to NHTSA for CT was weighted using older traffic counts and therefore differs from the percentage reported here by a small amount. 


\section{CT Statewide Nighttime Belt Use}

$85 \%$

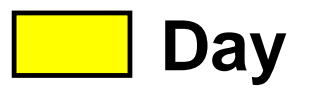

Night
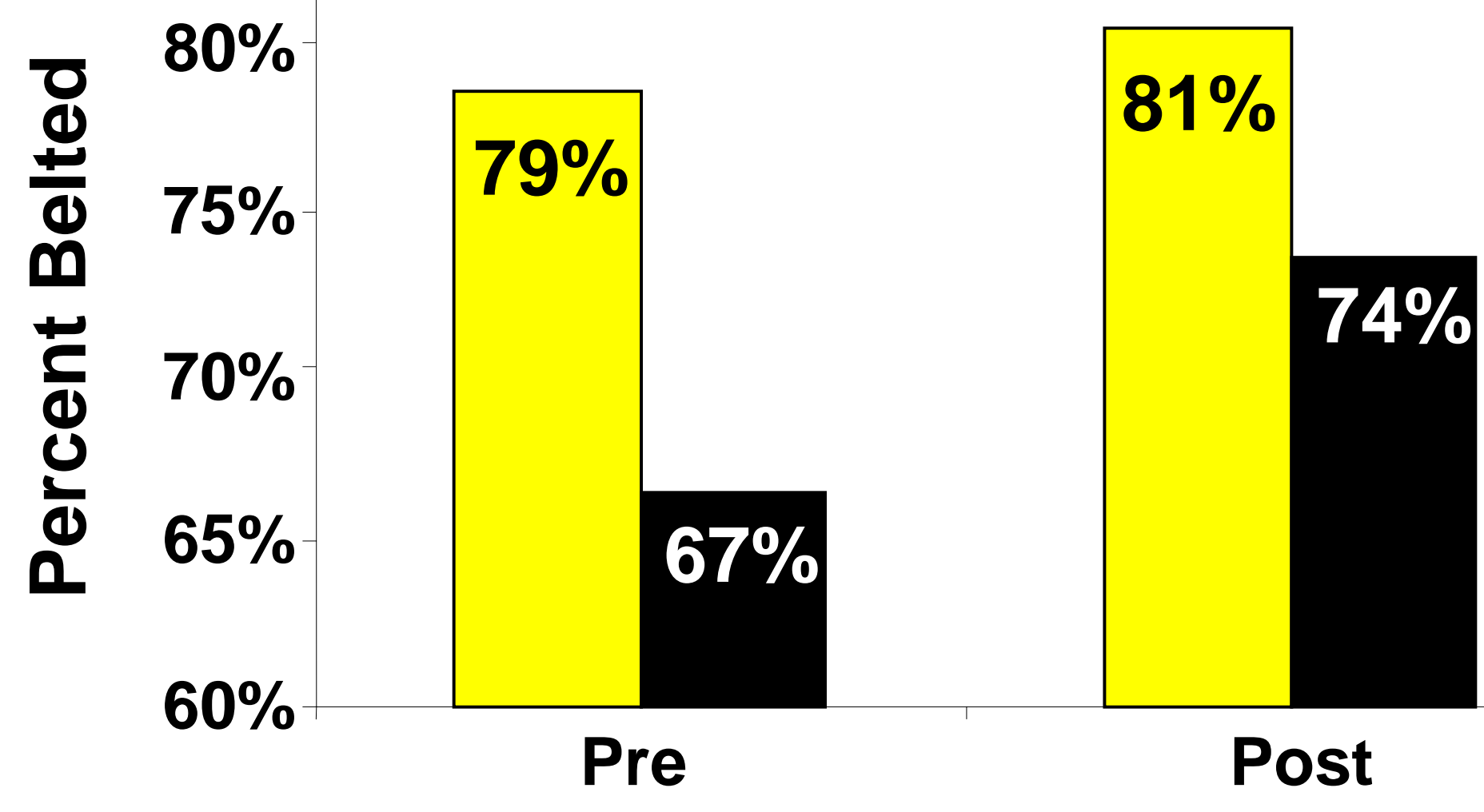

Unweighted Values 


\section{CT Statewide Nighttime Belt Use}

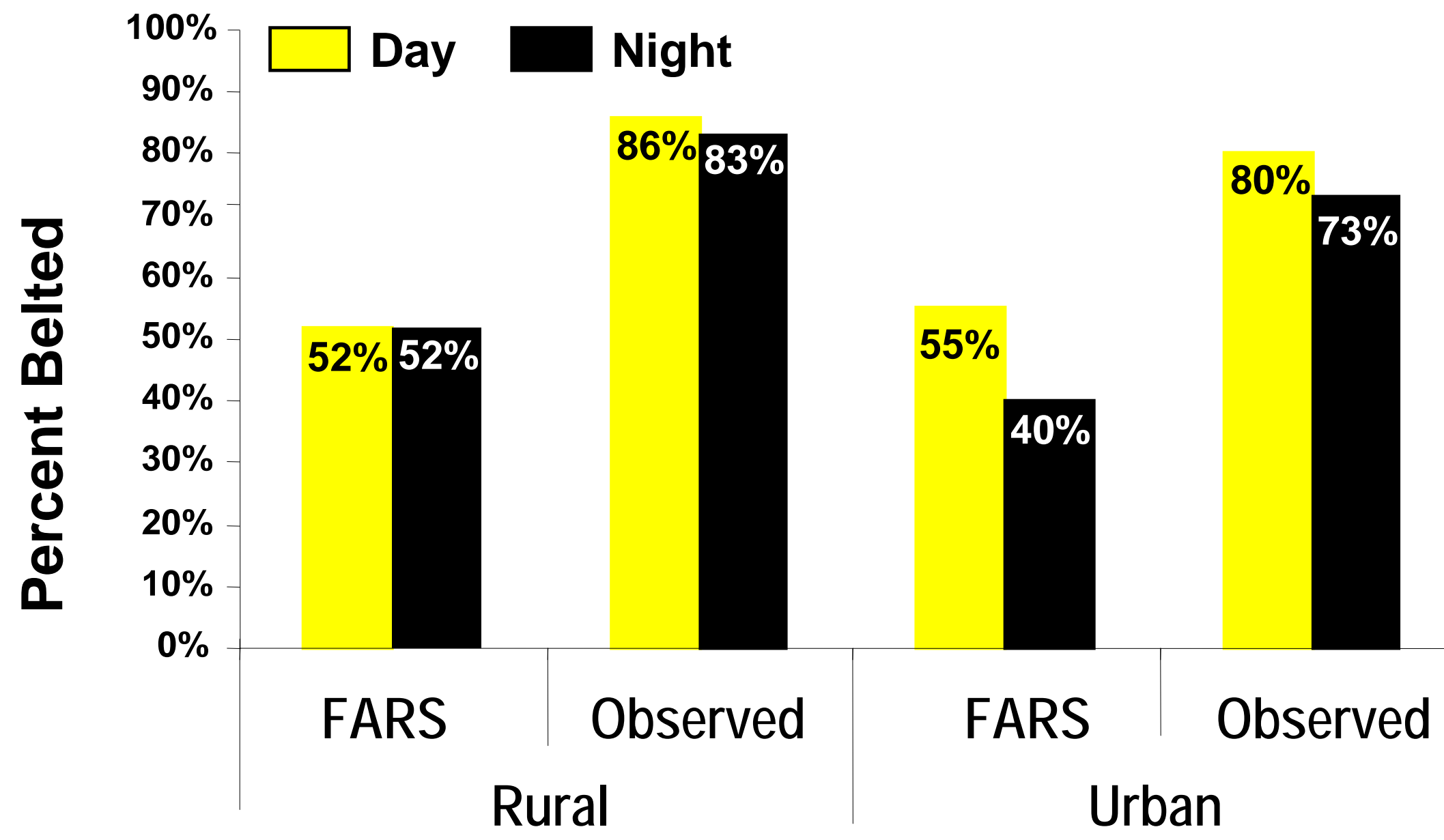




\section{Limitations}

- One state

- One time

- Limited number of survey sites 


\section{Questions?}
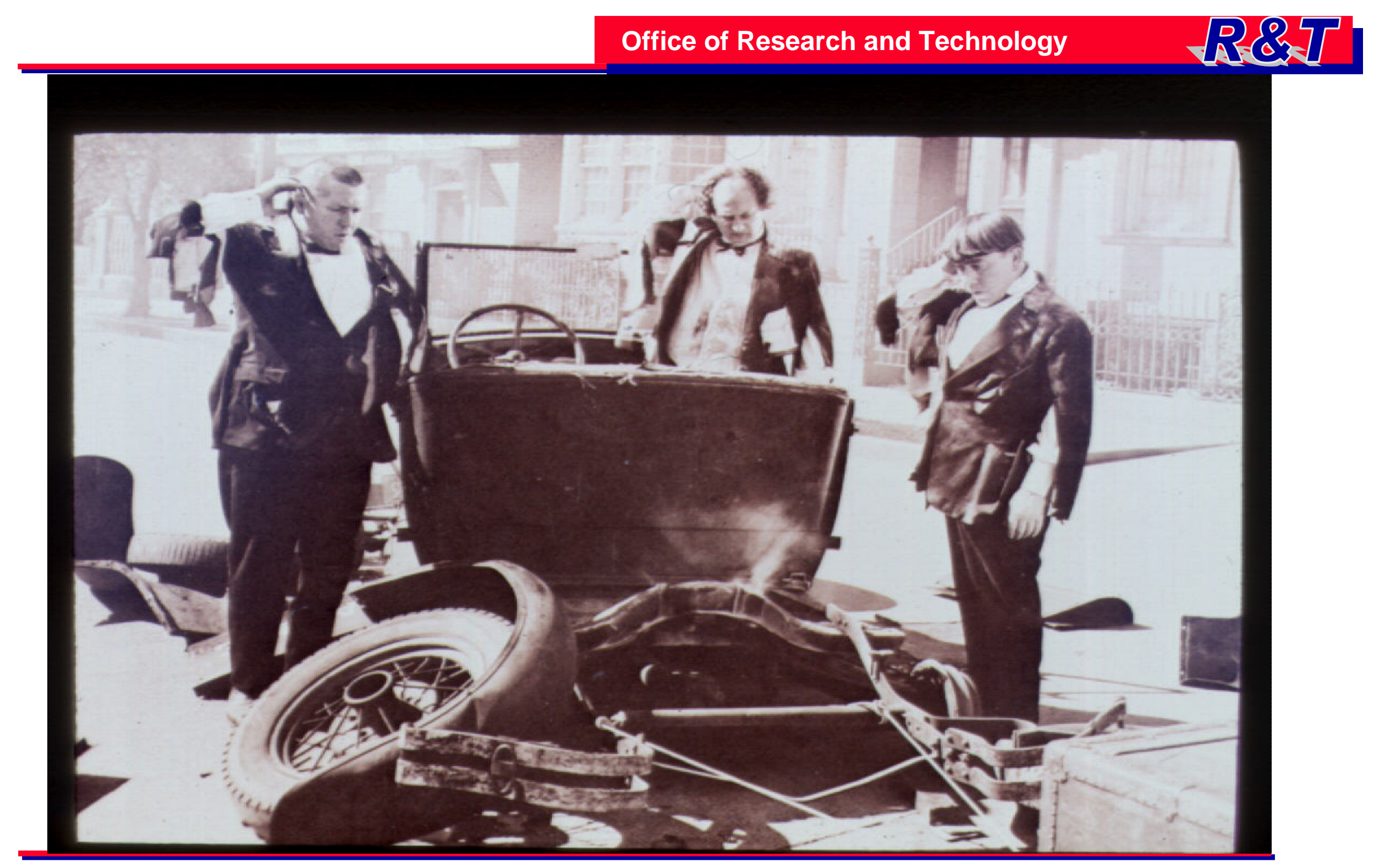


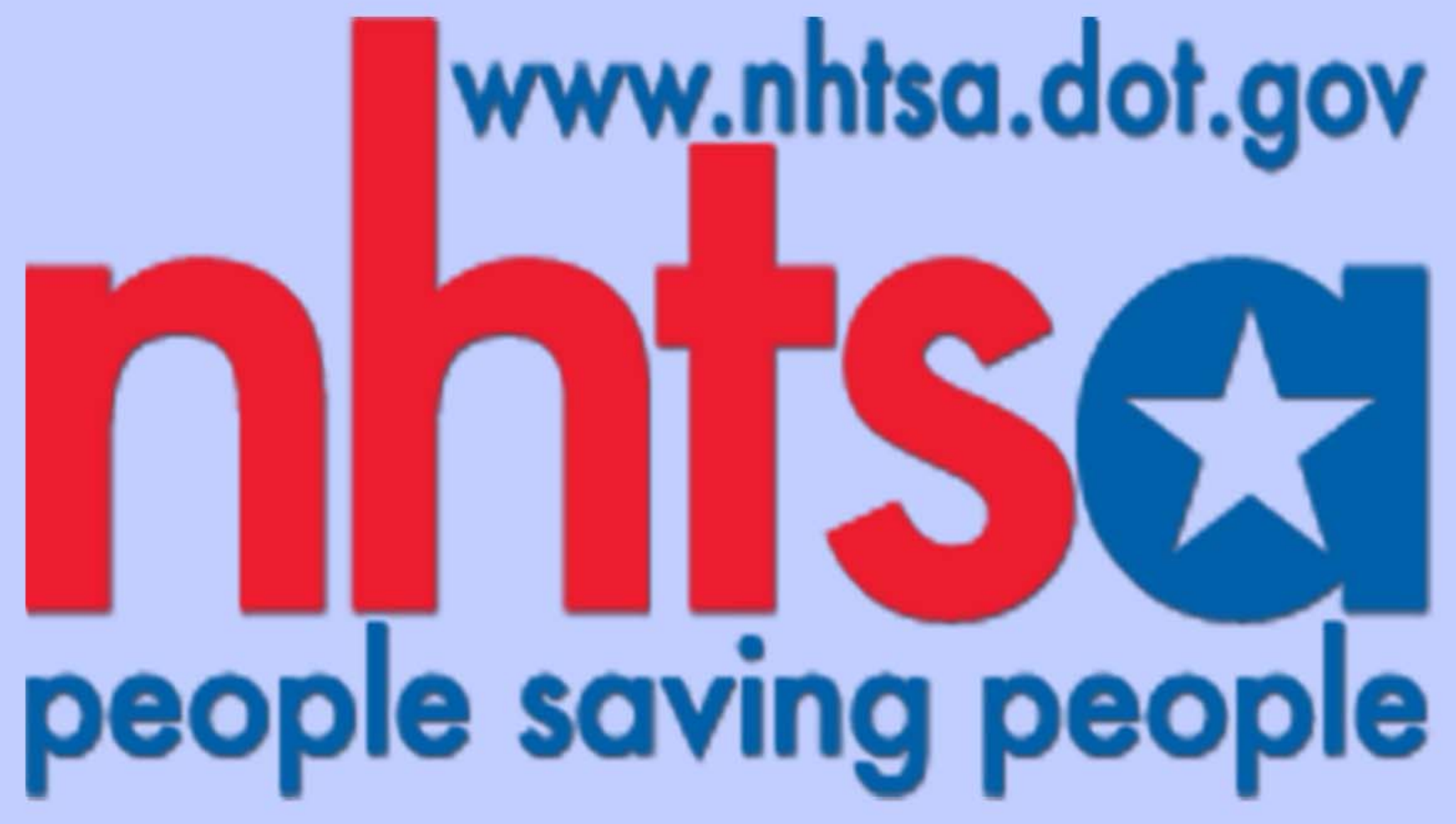

